\title{
Cardiovascular actions of chicken-meat extract in normo- and hypertensive rats
}

\author{
Meng-Kwoon Sim* \\ Department of Pharmacology, Faculty of Medicine, National University of Singapore, Singapore 119260
}

(Received 5 September 2000 - Revised 20 December 2000 - Accepted 4 February 2001)

\begin{abstract}
The cardiovascular actions of a commercial chicken-meat extract known as Brand's Essence of Chicken (Cerebos Pacific Ltd, Singapore; BEC) were investigated in normo- and hypertensive rats. The spontaneously-hypertensive rat (SHR), Wistar Kyoto rat (WKY) and Sprague Dawley rat (SD) were used. The effect of oral feeding of BEC on hypertension, cardiac hypertrophy and arteriosclerosis in these animals was studied. The data showed the following effects of oral feeding of BEC: (1) feeding for $30 \mathrm{~d}$ did not affect the blood pressure and heart rate (determined telemetrically) of adult SHR and WKY; (2) feeding for $90 \mathrm{~d}$ did not affect the development of hypertension in 1-month-old prehypertensive SHR; (3) feeding for $4 \mathrm{~d}$ dose-dependently $(0 \cdot 2-$ $3.2 \mathrm{ml} / \mathrm{kg}$ per d) attenuated cardiac hypertrophy in experimentally-induced (coarctation of the abdominal aorta) cardiac hypertrophic SD; (4) feeding to 1-month-old prehypertensive SHR for 11 months did not affect the age-related development of hypertension in this animal; (5) there was significant attenuation of the age-related development of hypertension (determined by tailcuff plethysmography) in the WKY $(P=0.011)$ when the animals drank an average of $7.5 \mathrm{ml}$ $\mathrm{BEC} / \mathrm{kg}$ body weight per $\mathrm{d}$, measured during the last 2 months of the 11-month treatment period; (6) there was chronic, as in the previous treatment, attenuation of the age-related development of cardiac hypertrophy and arteriosclerosis (quantified morphometrically) in the SHR when the animals drank an average of $2.4 \mathrm{ml} \mathrm{BEC} / \mathrm{kg}$ per d, measured during the last 2 months of the 11month treatment period. A parallel study using laboratory-prepared chicken-meat and pork extracts showed that the former, but not the latter, attenuated cardiac hypertrophy in experimentally-induced cardiac hypertrophic SD. These findings, showing that chicken-meat extract (both BEC and laboratory prepared) could have anti-cardiac hypertrophic, anti-hypertensive and anti-arteriosclerotic actions, were unexpected and provoking, and would challenge nutritional scientists with an interest in meat consumption and cardiovascular diseases.
\end{abstract}

Chicken-meat extract: Cardiac hypertrophy: Arteriosclerosis: Hypertension

Angiotensin II, a peptide of eight amino acids, is a key component of the renin-angiotensin system. It is involved in the regulation of cardiovascular, renal and endocrine functions. Over the past decade it has become evident that other peptides may contribute to the spectrum of activities of the renin-angiotensin system. These peptides, such as angiotensin-(3-8), angiotensin-(1-7) and angiotensin-(2$10)$, have biological actions that may be similar or more often opposite to those of angiotensin II; for example, they oppose the vascular constricting and growth-promoting effects of angiotensin II (Sim \& Radhakrishnan, 1994a; Ardaillou \& Chansel, 1996; Freeman et al. 1996; Ferrario et al. 1997; Min et al. 2000). In the present study, we investigated the effects of a commercial chicken-meat extract known as Brand's Essence of Chicken (BEC;
Cerebos Pacific Ltd, Singapore) on blood pressure, cardiac hypertrophy and arteriosclerosis in normo- and hypertensive rats. The rationale of the study was based on: (1) the assumption that BEC contains active peptides that could affect the cardiovascular system; (2) the astronomical annual sale of over 100 million bottles of BEC in the South-East Asia region (production data supplied by the manufacturer of BEC); (3) the paucity of information on the long-term effect of BEC consumption and our recent scientific reports on the biological activities of BEC (Xu \& Sim, 1997). In addition, studies in human subjects have shown that BEC increased the metabolic rate in healthy volunteers (Geissler, 1988; Geissler et al. 1989) and increased the restoration of serum Fe after blood donation in females (Williams \& Schey, 1993). These studies

Abbreviations: BEC, Brand's Essence of Chicken; HI, hypertrophy index; SD, Sprague Dawley rat; SHR, spontaneously hypertensive rat; WKY, Wistar Kyoto rat.

* Corresponding author: Dr Meng-Kwoon Sim, fax +65 773 0579, email phcsimmk@nus.edu.sg 
support, to a certain extent, the notion that BEC is an effective nutritional supplement for physical stress. The present study investigated, for the first time, the effects of BEC in diseased states in animals.

\section{Methods}

The use of animals in this investigation conforms to the Guide for the Care and Use of Laboratory Animals published by the National Institutes of Health (1996).

The effects of BEC on the following variables were investigated: (1) the blood pressure of adult spontaneouslyhypertensive rats (SHR) and their normotensive control Wistar Kyoto rats (WKY); (2) the development of blood pressure in the SHR from 1 month to 4 months of age; (3) the experimentally induced cardiac hypertrophy in Sprague Dawley rats (SD); (4) the age-related development of hypertension, cardiac hypertrophy and arteriosclerosis in the SHR and normotensive WKY. SHR and WKY were obtained from the Animal Resource Centre, Murdoch, Western Australia, Australia. SD were obtained from the National University of Singapore Animal Centre.

\section{Effects on blood pressure of adult spontaneously- hypertensive and Wistar Kyoto rats}

The 4-month-old male SHR and their normotensive control WKY were used. A telemetry blood pressure transmitter (Data Sciences International, St Paul, MN, USA) was implanted into each rat as described previously (Sim \& Radhakrishnan, 1994b). The transmitter monitored the blood pressure and heart rate and sent these measurement via a receiver to a computer that recorded and displayed the ongoing heart rate and blood pressure.

At $2 \mathrm{~d}$ following the implantation, each rat was placed in a cage that was in turn placed over a telemetry receiver. The heart rate and blood pressure of each rat were continuously monitored for a period of $15 \mathrm{~d}$. Fresh rat food and tap water were provided every day. Following this period, $0.25 \mathrm{ml} \mathrm{BEC} / 100 \mathrm{~g}$ body weight was administered orally to each rat for $30 \mathrm{~d}$. Oral administration was carried out using a $1 \mathrm{ml}$ syringe with a blunt needle, and each dose was given in a minimum of $0.5 \mathrm{ml}$. The heart rate and blood pressure of the rats were monitored during the $30 \mathrm{~d}$ feeding period and $15 \mathrm{~d}$ after the feeding of BEC.

\section{Effects on development of blood pressure}

BEC $(0.25 \mathrm{ml} / 100 \mathrm{~g}$ body weight daily) was administered orally to six 4-week-old SHR for a period of $90 \mathrm{~d}$ and saline $(9 \mathrm{~g} \mathrm{NaCl} / \mathrm{l})$ was administered to another six SHR for the same period. The weight of the rats was determined every week and the dose of BEC was adjusted accordingly. Following this period of treatment, each rat was implanted with a telemetry blood-pressure transmitter and the blood pressure was monitored as described earlier for $15 \mathrm{~d}$.

\section{Effects on experimentally-induced cardiac hypertrophy}

The abdominal aortas of 3-month-old SD were coarcted to the size of a 23-gauge hypodermic needle with a silk thread as described previously (Sim \& Min, 1998). Briefly, each animal was anaesthetized with pentobarbital $(5 \mathrm{mg} / 100 \mathrm{~g}$, intraperitoneally). An incision was made in the ventral abdominal wall to access the suprarenal portion of the abdominal aorta. This portion of the abdominal aorta was dissected free and a blunt 23-gauge needle was placed adjacent to the aorta. A ligature was placed around the blunt needle and the aorta. The blunt needle was then removed, leaving the aorta constricted to the size of the needle. The resulting coarctation resisted the normal flow of blood from the heart to the lower portion of the body and placed an extra load on the heart. This extra load is believed to cause the heart, especially the left ventricle, to hypertrophy.

Following the operation, one of the following doses ( $\mathrm{ml} /$ $100 \mathrm{~g}$ body weight per d) of BEC: $0 \cdot 01,0 \cdot 02,0 \cdot 04,0 \cdot 08$, $0 \cdot 16,0 \cdot 32$, was administered orally to each animal for $4 \mathrm{~d}$. Saline was administered to control animals with coarcted abdominal aorta instead of BEC. Sham-operated animals underwent the same surgical operation but their aortae were not coarcted. In animals in which BEC was coadministered with indomethacin, $30.4 \mu \mathrm{mol} / 300 \mathrm{~g}$, the drug was administered intraperitoneally. This dose was based on the efficacy obtained in earlier experiments (Sim \& Min, 1998).

On day 4 following the coarctation of the abdominal aorta, the animal was again anaesthetized with pentobarbital and the carotid and femoral blood pressures were determined via a carotid artery catheter and a femoral artery catheter, respectively. Each catheter was connected to a Gould Statham (P23 ID, Essex, UK) pressure transducer. The transducers were in turn connected to a MacLab Quad Bridge Amplifier coupled to a MacLab/8 Virtual Instrument System which displayed the mean arterial blood pressure. The difference in the two readings indicated the extent of coarctation. The heart of each animal was then excised and the weights of the ventricles were determined. The index of the ventricle weight $(\mathrm{mg})$ over the body weight of the animal $(\mathrm{g})$ was taken as the hypertrophy index (HI). For sham-operated animals the HI was approximately 2.5 ; for aorta-coarcted animals the HI was significantly greater.

In a parallel experiment the effects of laboratoryprepared chicken-meat and pork extracts on experimentally-induced cardiac hypertrophy in rats was carried out. Chicken breast and fillet pork were purchased from the local market. The meat was cut into $1.5 \mathrm{~cm}$ cubes, and thoroughly washed with purified water. Chicken meat or pork $(600 \mathrm{~g})$ in 1.2 litre purified water was brought to the boil in a 2 litre conical flask and maintained at moderate boiling for $7 \mathrm{~h}$. A volume of 150-200 ml extract was obtained. The extract was decanted into $50 \mathrm{ml}$ tubes and centrifuged at $1500 \mathrm{~g}$ for $15 \mathrm{~min}$ at room temperature. The supernatant was transferred to a separating funnel and the small amount of lipid was removed. The lipid- and sediment-free meat extract was place in equal amounts into $4 \mathrm{ml}$ vials and sterilized in boiling water for $1 \mathrm{~h}$. The protein content in the chicken-meat and pork extract was determined by the Bio-Rad protein assay (Bio-Rad) and found to be 1.73 and $1.94 \mathrm{mg} / \mathrm{ml}$, respectively. The effect of the meat extracts on the experimentally-induced cardiac hypertrophy in rats was determined as described earlier. 
Table 1. Composition of Brand's Essence of Chicken (data provided by manufacturer, Cerebos Pacific Ltd)

\begin{tabular}{lc}
\hline Ingredient & Amount \\
\hline Protein and peptide $(\mathrm{mg} / \mathrm{ml})$ & $83 \cdot 0$ \\
Amino acid $(\mathrm{free} ; \mathrm{mg} / \mathrm{ml})$ & $3 \cdot 1$ \\
Hexose $(\mathrm{mg} / \mathrm{ml})$ & $0 \cdot 8$ \\
Lipid $(\mathrm{mg} / \mathrm{ml})$ & 0.4 \\
Mineral $(\mu \mathrm{g} / \mathrm{ml})$ & \\
Ca & 26 \\
Fe & 1 \\
Mg & 32 \\
Zn & 2 \\
$\mathrm{~K}$ & 1740 \\
$\mathrm{Na}$ & 550 \\
$\mathrm{Cl}$ & 1340 \\
$\mathrm{P}$ & 480 \\
Cu & 2 \\
Mn & 5 \\
$\mathrm{~S}$ & 500 \\
Se & 0.05 \\
Vitamins $(\mathrm{mg} / \mathrm{kg})$ & \\
Riboflavin & \\
Vitamin $\mathrm{B}_{6}$ & 1.0 \\
Vitamin $\mathrm{B}_{12}$ & 0.37 \\
Niacin & 0.002 \\
Folic acid & 6.4 \\
Vitamin C & $0 \cdot 15$ \\
\hline
\end{tabular}

\section{Effect on the age-related development of hypertension, cardiac hypertrophy and arteriosclerosis}

The animals used were 1-month-old SHR and their normotensive control WKY. Animals were housed three or four in a cage and had free access to rat chow and either 2.5 or $10 \%(\mathrm{v} / \mathrm{v})$ BEC instead of water for 11 months (until the animals were 1 year old). Control animals were given water instead of BEC. The 2.5 and $10 \%(\mathrm{v} / \mathrm{v}) \mathrm{BEC}$ solutions were prepared by diluting bottled BEC with sterilized distilled water. Rats drank the diluted BEC solutions from sterilized feeding bottles placed in the cages. Animals were supplied with freshly-prepared solutions of BEC daily. In another experiment, adult SHR (5 months old) were fed with $10 \%$ (v/v) BEC for 7 months (until the animals were 1 year old).

The daily consumption of BEC was recorded, and the weight of the animals was recorded weekly for the first 30 weeks and monthly until the end of the experiment.

A week before the 11th month of the experiment, the blood pressure of each animal was determined by the tailcuff method. At the end of 11 months both the water- and BEC-fed animals were killed by gassing with $\mathrm{CO}_{2}$. The weights of the body and ventricles of each animal were recorded and the $\mathrm{HI}$ was determined. A $3 \mathrm{~cm}$ section (measured from the left renal artery) of the abdominal aorta was removed from each rat and fixed in $4 \%(\mathrm{v} / \mathrm{v})$ paraformaldehyde and $1 \%(\mathrm{v} / \mathrm{v})$ glutaraldehyde. The aorta was processed for embedding in paraffin. Sections (10 $\mu \mathrm{m}$ thick) were prepared and stained with toluidine blue. Fifty such sections, cut from the distal end of the artery, were used for quantification.

The area of the medial smooth muscle cells was quantified morphometrically using an image analysis system consisting of a BX40 light microscope (Olympus, Japan) fitted with a KY-F55B colour video camera (JVC, Japan) and a Pentium $166 \mathrm{MHz} / \mathrm{MMX}$ microcomputer (Datamini, Singapore) installed with an Image Pro Plus 3.0 System (Media Cybernetics, Silver Spring, MD, USA) for Windows $95^{\mathrm{TM}}$.

\section{Results}

Table 1 gives the nutritional composition of BEC (data provided by Cerebos Pacific Ltd).

\section{Effects on blood pressure of adult spontaneously- hypertensive and Wistar Kyoto rats}

Table 2 shows the mean heart rates and blood pressures (taken between 18.00 and 24.00 hours, daily) for six animals for the period before, during and after the oral administration of BEC. BEC did not affect the blood pressure and heart rate of the normo- and hypertensive rats to any significant extent $(P>0 \cdot 05$; ANOVA).

\section{Effects on development of blood pressure}

Table 3 shows the mean heart rates and blood pressures (taken between 18.00 and 24.00 hours, daily) for the six BEC-treated and control animals during the $15 \mathrm{~d}$ period

Table 2. Effect of Brand's Essence of Chicken (Cerebos Pacific Ltd) on the heart rate and mean arterial pressure of adult spontaneously-hypertensive rats and Wistar Kyoto rats*

(Mean values with their standard errors for six rats)

\begin{tabular}{|c|c|c|c|c|}
\hline & \multicolumn{2}{|c|}{$\begin{array}{l}\text { Arterial blood pressure } \\
(\mathrm{mmHg})\end{array}$} & \multicolumn{2}{|c|}{$\begin{array}{l}\text { Heart rate } \\
\text { (beats/min) }\end{array}$} \\
\hline & Mean & SE & Mean & SE \\
\hline \multicolumn{5}{|c|}{ Spontaneously-hypertensive rats } \\
\hline Before treatment & 164 & $2 \cdot 2$ & 282 & 4.0 \\
\hline During treatment & 162 & 1.7 & 276 & 2.9 \\
\hline After treatment & 161 & 1.6 & 276 & 3.7 \\
\hline \multicolumn{5}{|l|}{ Wistar-Kyoto rats } \\
\hline Before treatment & 107 & 1.6 & 272 & 2.5 \\
\hline During treatment & 106 & $1 \cdot 8$ & 267 & $2 \cdot 3$ \\
\hline After treatment & 105 & $1 \cdot 3$ & 268 & $2 \cdot 4$ \\
\hline
\end{tabular}

${ }^{*}$ For details of animals and experimental procedures, see p. 98. 
Table 3. Effect of Brand's Essence of Chicken (Cerebos Pacific Ltd) on the development of hypertension in spontaneously-hypertensive rats*

(Mean values with their standard errors for six rats)

\begin{tabular}{|c|c|c|c|c|}
\hline & \multicolumn{2}{|c|}{$\begin{array}{l}\text { Arterial blood pressure } \\
(\mathrm{mmHg})\end{array}$} & \multicolumn{2}{|c|}{$\begin{array}{l}\text { Heart rate } \\
\text { (beats } / \mathrm{min} \text { ) }\end{array}$} \\
\hline & Mean & SE & Mean & SE \\
\hline Rats administered saline $(9 \mathrm{~g} \mathrm{NaCl} / \mathrm{l})$ & 164 & $5 \cdot 3$ & 276 & $5 \cdot 6$ \\
\hline Rats administered BEC & 165 & $5 \cdot 1$ & 278 & 3.49 \\
\hline
\end{tabular}

${ }^{*}$ For details of animals and experimental procedures, see p. 98.

following $90 \mathrm{~d}$ oral BEC administration. BEC did not affect the development of hypertension in the SHR significantly $(P>0.05$; Student's $t$ test $)$.

\section{Effects on experimentally-induced cardiac hypertrophy}

Fig. 1 shows that oral feeding of BEC attenuated cardiac hypertrophy in SD with the coarcted abdominal aorta. The attenuation was dose-dependent and the maximum effect was attained at $0.4 \mathrm{ml} \mathrm{BEC} / \mathrm{kg}$. Coadministration of indomethacin $(30.4 \mathrm{~mol} / 300 \mathrm{~g})$ with BEC did not affect the anti-cardiac hypertrophic action of the latter. Oral

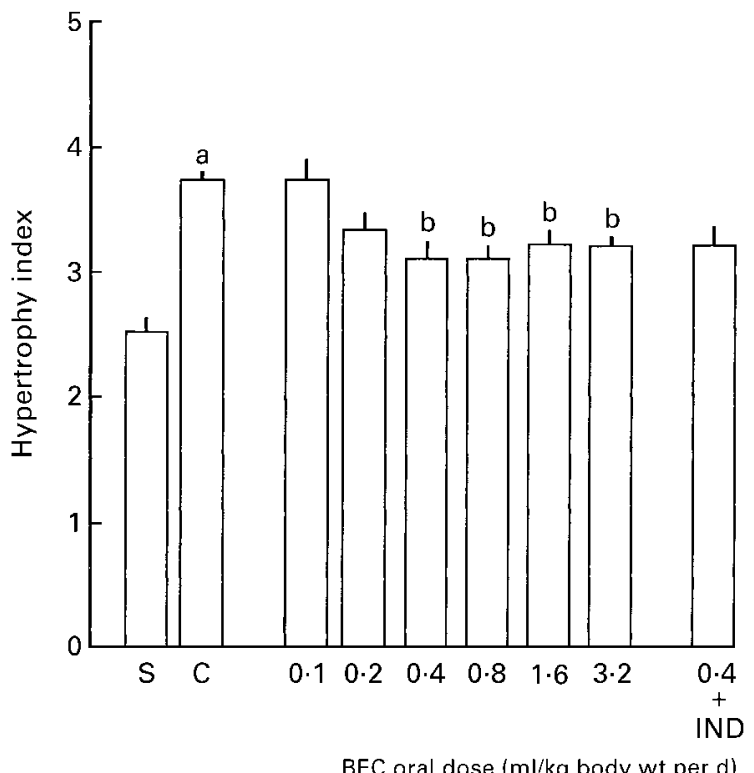

Fig. 1. Effects of Brand's Essence of Chicken (Cerebos Pacific Ltd; $\mathrm{BEC}$ ) on cardiac hypertrophy in Sprague Dawley rats. Hypertrophy index = ventricle weight $(\mathrm{mg}) /$ body weight $(\mathrm{g})$. Values are means with their standard errors represented by vertical bars for six animals. Sham-operated animals (S) underwent the surgical operation but not the coarctation of the abdominal aorta. Control animals $(\mathrm{C})$ underwent coarctation of the abdominal aorta and were given saline $(9 \mathrm{~g}$ sodium chloride/l) instead of BEC. The other animals were administered BEC at the indicated doses for $4 \mathrm{~d}$. BEC $(0.4 \mathrm{ml} / \mathrm{kg}$ per d) was co-administered with indomethacin $(30.4 \mu \mathrm{mol} / 300 \mathrm{~g}$; IND). For details of animals and procedures, see p. 98. ${ }^{a, b}$ Mean values with unlike superscript letters were significantly different $(P=0.001,0.0002,0.0015$ and 0.0002 for $\mathrm{C} v .0 .4,0.8,1.6,3.2 \mathrm{ml} /$ $\mathrm{kg}$ body weight per d respectively; Student's $t$ test with Bonferroni adjustments). Mean value for $0.4 \mathrm{ml} / \mathrm{kg}$ body weight per $\mathrm{d}+\mathrm{IND}$ was not significantly different from the corresponding dose given in the absence of IND. feeding of laboratory-prepared chicken-meat extract, but not pork extract, similarly attenuated the cardiac hypertrophy in SD (Fig. 2).

\section{Effect on the age-related development of hypertension, cardiac hypertrophy and arteriosclerosis}

There were no significant differences between the corresponding weights of the water- and BEC-fed animals (data not shown). Fig. 3 shows the mean volume of water and BEC consumed during the last $60 \mathrm{~d}$ of the experiment. SHR fed with diluted BEC consumed a significantly $(P<0.001)$ larger volume of fluid compared with those fed with water. However, in the case of the WKY, rats fed with diluted BEC consumed a significantly $(P=0.005)$ smaller volume of fluid compared with those fed with water.

Figs. 4 and 5 show the blood pressure and $\mathrm{HI}$ of the water- and BEC-fed animals. BEC had no effect on the blood pressure of the SHR (Fig. 4). However, there was a significant $(P=0.011)$ attenuation of the age-related increase in blood pressure in the normotensive WKY fed with $10 \%(\mathrm{v} / \mathrm{v})$ BEC (Fig. 5). SHR fed with $2.5 \%(\mathrm{v} / \mathrm{v})$ BEC had significantly $(P<0.001)$ lower HI. With the $10 \%(\mathrm{v} / \mathrm{v}) \mathrm{BEC}$, only rats fed from 5 months to 1 year of

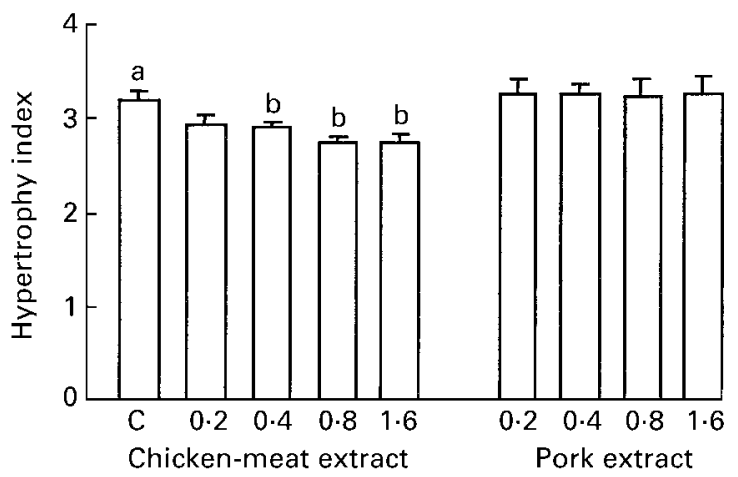

Oral dose $(\mathrm{ml} / \mathrm{kg}$ body wt per d)

Fig. 2. Effects of laboratory-prepared chicken-meat and pork extract on cardiac hypertrophy in Sprague Dawley rats. Hypertrophy index $=$ ventricle weight $(\mathrm{mg}) / \mathrm{body}$ weight $(\mathrm{g})$. Values are mean standard error obtained from six animals. Control animals $(C)$ were given saline ( $9 \mathrm{~g}$ sodium chloride/l) instead of meat extract. The other animals were fed either chicken-meat or pork extract at the indicated doses for $4 \mathrm{~d}$. For details of animals and procedures, see $p$. 98. ${ }^{a, b}$ Mean values with unlike superscript letters were significantly different $(P=0.011,0.0019$ and 0.0103 for $C v .0 .4,0.8$ and $1.6 \mathrm{ml}$ chicken-meat extract $/ \mathrm{kg}$ body weight per $\mathrm{d}$; Student's $t$ test with Bonferroni adjustments). 


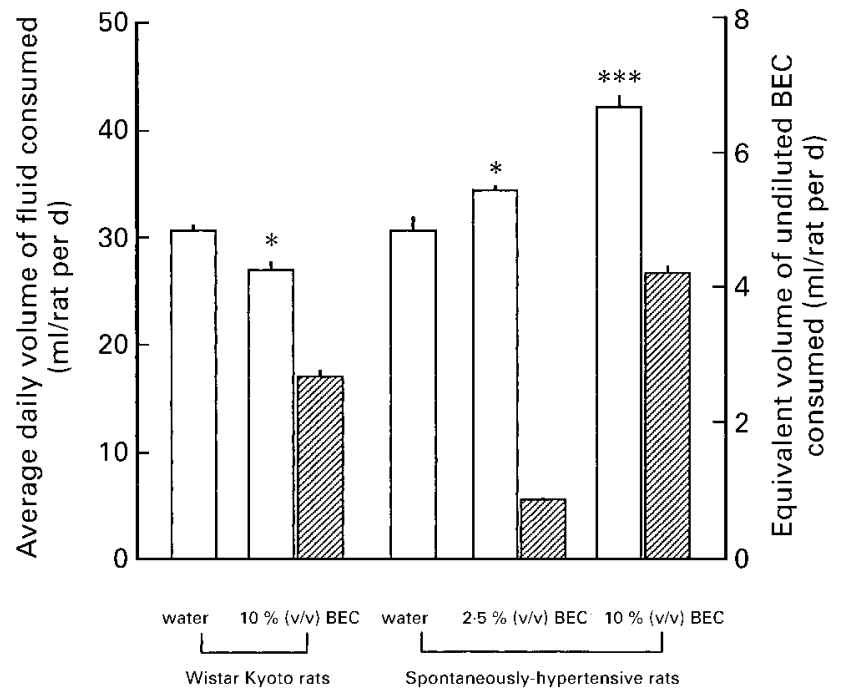

Fig. 3. Average daily consumption of fluid (water and diluted Brand's Essence of Chicken (Cerebos Pacific Ltd; BEC)) during the last $60 \mathrm{~d}$ of the experiment. Values are means with their standard errors represented by vertical bars for twelve animals. ( $\square$ ) Equivalent volume of undiluted BEC consumed. For details of animals and procedures, see p. 98 . Mean values were significantly different from those for the corresponding water-fed group: $\left({ }^{\star} P=0.005,{ }^{\star \star \star} P<\right.$ 0.001 Student's $t$ test).

age showed a significant $(P=0 \cdot 011)$ decrease in HI. There was no significant difference in the HI of the saline- and BEC-fed WKY.

Fig. 6 shows the thickness of the aortic smooth muscle layer in the saline- and BEC-treated animals. BEC significantly $(P<0.001)$ attenuated the age-related development of arteriosclerosis in the SHR.

\section{Discussion}

The oral route was used because oral feeding of BEC has also been shown to be effective in increasing the level of

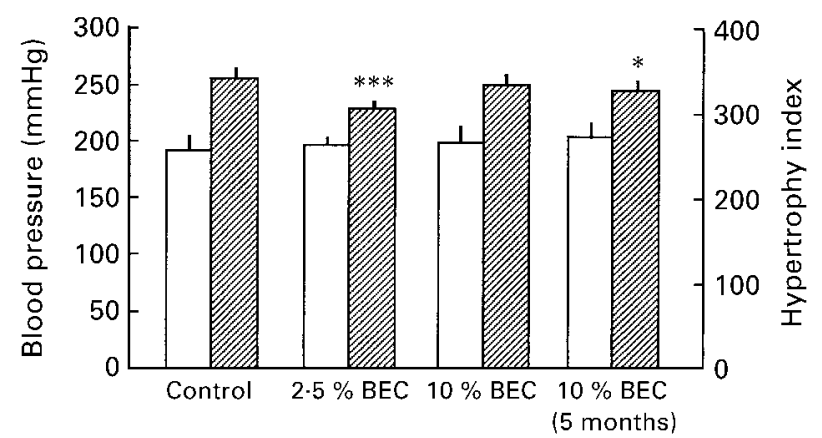

Fig. 4. Effect of Brand's Essence of Chicken (Cerebos Pacific Ltd; BEC) on blood pressure ( $\square$ ) and hypertrophy index (g ventricle weight $/ 100 \mathrm{~g}$ body weight; ( in male spontaneously-hypertensive rats. Control, rats given water; $2.5 \% \mathrm{BEC}$, rats given $2.5 \%(\mathrm{v} / \mathrm{v})$ BEC; $10 \%$ BEC, rats given $10 \%$ (v/v) BEC; $10 \%$ BEC (5 months), rats given $10 \%(\mathrm{v} / \mathrm{v})$ BEC from 5 months to 1 year old. For details of animals and procedures, see p. 98. Values are means with their standard errors represented by vertical bars for twelve animals. Mean values were significantly different from those for the corresponding controls: $\left({ }^{\star} P=0.011\right.$, ${ }^{\star * \star} P<0.001$ ) (Student's $t$ test).

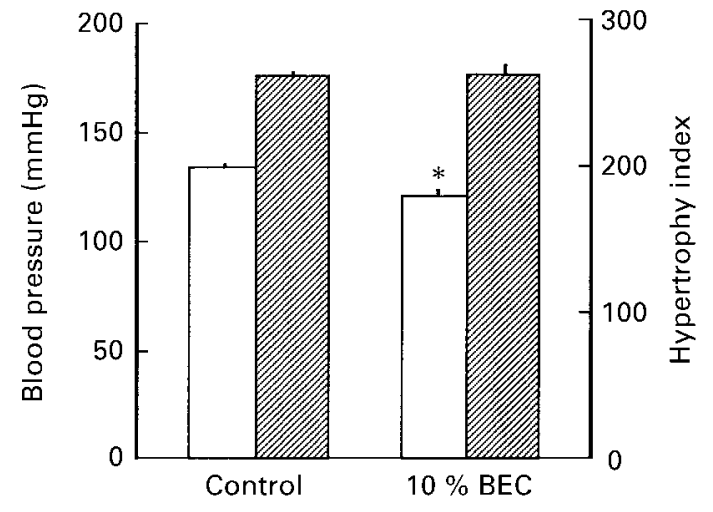

Fig. 5. Effect of Brand's Essence of Chicken (Cerebos Pacific Ltd; BEC) on blood pressure ( $\square$ ) and hypertrophy index ( $g$ ventricle weight/100 g body weight; 四) in male Wistar Kyoto rats. Control, rats given water; $10 \% \mathrm{BEC}$, rats given $10 \%(\mathrm{v} / \mathrm{v})$ BEC. For details of animals and procedures, see p. 98. Values are means with their standard errors represented by vertical bars for twelve animals. Mean value was significantly different from that for the control: ${ }^{*} P=$ 0.011 (Student's $t$ test).

5-hydroxytryptamine in the cerebral spinal fluid in rats $(\mathrm{Xu}$ \& Sim, 1997). In man BEC was consumed orally.

Feeding BEC to adult (4-month-old) SHR with established hypertension for 1 month and to 4-week-old prehypertensive SHR for $90 \mathrm{~d}$ did not affect the blood pressure and heart rate of these animals. As 4 weeks to 4

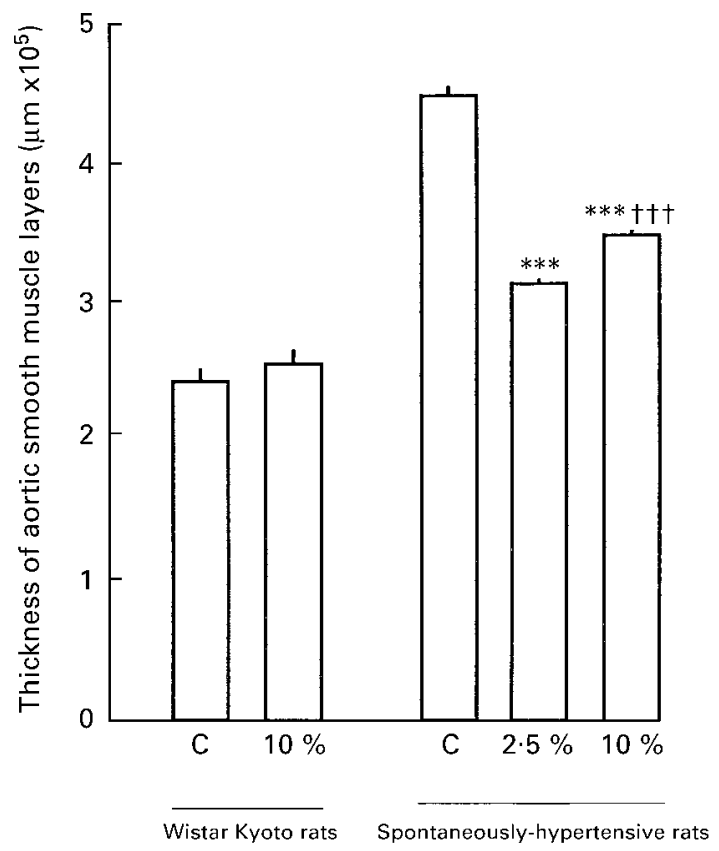

Fig. 6. Effect of Brand's Essence of Chicken (Cerebos Pacific Ltd; BEC) on the age-related development of arteriosclerosis in Wistar Kyoto rats and spontaneously-hypertensive rats. $\mathrm{C}$, rats given water; $2.5 \%$ and $10 \%$, rats given 2.5 and $10 \%(\mathrm{v} / \mathrm{v})$ BEC respectively. For details of animals and procedures, see p. 98 . Values are means with their standard errors represented by vertical bars for twelve animals. Means values were significantly different from that for the control: ${ }^{* * \star} P<0.001$ (ANOVA, post hoc Newman Keuls test). Mean value was significantly different from that for $2.5 \%$; ††† $P=0.001$ (ANOVA, post hoc Newman Keuls test). 
months straddled the period in which hypertension developed in these animals, the results indicate that BEC did not affect the development of hypertension in the young SHR and the developed hypertension in adult SHR. The dose of $0.25 \mathrm{ml} / 100 \mathrm{~g}$ body weight used in these rat experiments is equivalent to 2.5 bottles $(70 \mathrm{ml} / \mathrm{bottle})$ BEC/70 $\mathrm{kg}$ body weight in man. The findings may suggest that moderate consumption of BEC (less than two bottles/d) would not aggravate hypertension in hypertensive individuals.

In the acute experimentally-induced cardiac hypertrophy experiment, oral feeding of BEC dose-dependently attenuated the hypertrophy. This is the first demonstration of such an effect, and the possible mechanisms of action are not known. Based on similar effects observed with desaspartate-angiotensin I (Sim \& Min, 1998) and other compounds that act on the renin-angiotensin system to attenuate the effects of angiotensin II (Mizuno et al. 1992; Ruzicka et al. 1994; Ishiye et al. 1995), the likelihood of BEC peptides causing the anti-cardiac hypertrophy via similar actions is strong. However, the inability of $30.4 \mu \mathrm{mol}$ indomethacin to attenuate the anti-cardiac effect of BEC (as compared with earlier results obtained with desaspartate-angiotensin I; Sim \& Min, 1998) suggests that the actions of BEC may not be due only to the anticipated desaspartate-angiotensin I, and is likely to be caused by more than one compound. Des-aspartate-angiotensin I has been shown to act via an indomethacin-sensitive angiotensin receptor and its anti-cardiac hypertrophic action is inhibited by indomethacin (Sim \& Min, 1998).

A parallel study carried out using laboratory-prepared chicken-meat and pork extracts showed that the latter extract was inactive, while significant anti-cardiac hypertrophic action was detected with the chicken-meat extract. Both extracts were prepared by the same methods protocols and contained comparable levels of soluble protein. The chicken-meat extract was found to be efficacious at doses that contained more than $1 \mathrm{mg}$ soluble protein. Although BEC contains a much higher level of soluble protein and presumably a higher level of peptides, a large part of these compounds would have been metabolized by the proteases and peptidases in the gastrointestinal tract. In an earlier study with des-aspartate-angiotensin I, we showed that the effective concentration of an orally-administered peptide would probably be lower than the $K_{m}$ of the gastrointestinal tract enzymes, i.e. the small amount of peptide that could not be digested by the enzymes was effective in producing the anti-cardiac hypertrophic action (Sim \& Min, 1998). Thus, it appears that the difference between the pork and chicken extracts is the absence of anti-cardiac hypertrophic compounds in the former and their presence in the latter. It is of interest to note that chicken meat has also been found to be different from pork and beef with regard to anserine:carnosine contents (Tinbergen \& Slump, 1976). The values for this ratio in beef, pork and chicken are $0.06: 0.2,0.02: 0 \cdot 1$ and $2 \cdot 2: 5.5$, respectively.

BEC contains no detectable fat and fatty acids. This factor is reflected in the absence of weight gain in animals that drank up to $4 \mathrm{ml} \mathrm{BEC/d}$. The preference of BEC solution over water seen in the SHR and the reverse situation seen in the WKY supports the contention that hypertensive animals, including man, have a liking for salty food.
Chronic feeding of BEC to normo- and hypertensive rats produced interesting positive results. The significant decrease in age-related hypertension $(P=0.011)$ seen in the WKY that drank an average of about $7.5 \mathrm{ml} / \mathrm{kg}$ body weight per $\mathrm{d}$ during the last $60 \mathrm{~d}$ of recording, and the absence of a similar effect in the SHR that drank an average of slightly over $12.3 \mathrm{ml} / \mathrm{kg}$ body weight per $\mathrm{d}$ in the corresponding period would suggest that the development of hypertension in the two animal species is different. The causes for any form of hypertension are multi-factorial and complex, and the finding that consumption of chicken-meat extract could attenuate the development of age-related hypertension is indeed a surprising finding, highlighting the paucity of information on meat and hypertension and the need to know more.

With regard to age-related development of cardiac hypertrophy, two facts need to be addressed. The agerelated cardiac hypertrophy in normotensive rats does not become obvious at 12 months (Younes et al. 1995; Corman et al. 1998). However, in SHR cardiac hypertrophy is significant at 12 months of age (Peters et al. 1984; Ieki et al. 1989). Hence, in the present study the WKY served as positive control animals, i.e. to determine whether BEC could induce cardiac hypertrophy. The data show that BEC did not accelerate the rate of cardiac hypertrophy in the WKY.

In the SHR, BEC attenuated the age-related development of cardiac hypertrophy. However, the attenuation was not dose dependent and the SHR that were fed $10 \%(\mathrm{v} / \mathrm{v})$ BEC had a higher HI than those fed with $2.5 \%$ (v/v) BEC. It is difficult to postulate the underlying causes for this observation but, based on our earlier finding that higher doses of des-aspartate-angiotensin I could inhibit its own anti-cardiac hypertrophic action (M-K Sim, unpublished results), the latter observation is not unique to BEC. A likely mechanism could be that, at higher doses, BEC compounds could act on low-affinity receptors that oppose the first effect (anti-hypertrophic). In addition, the duration of treatment is a factor that determined the efficacy of BEC, as SHR that were treated at 5 months of age onwards with $10 \%(\mathrm{v} / \mathrm{v}) \mathrm{BEC}$ had a lower HI than those treated at 1 month onwards. The causes remain unknown. This finding opens up new avenues for further research on chicken-meat extract and age-related cardiac hypertrophy.

Chronic feeding of BEC also produced a significant antiarteriosclerotic effect. The weakening of the effect with the higher dose $(10 \%, \mathrm{v} / \mathrm{v})$ of BEC is also seen, albeit less marked as compared with the anti-cardiac hypertrophic effect. This effect could be due to the terminallydetermined nature of the cardiomyocytes as compared with the proliferation-capable vascular smooth muscle cells.

In conclusion, the findings that chicken-meat extract could have anti-cardiac hypertrophic, anti-hypertensive and anti-arteriosclerotic actions are unexpected and provoking. The former property appears to be chicken meat-specific as pork extract lacked the anti-cardiac hypertrophic action. This unusual cardiovascular property of chicken meat seems to support the findings of other investigators showing that increased consumption of chicken meat, fish and vegetarian patties is effective in reducing the risk 
factors for coronary artery disease in man (Sperber et al. 1996). At the cellular level, chicken meat was shown to have high activity in stimulating the production of NO by macrophages (Miwa et al. 1997), which could contribute to its cardiovascular property. Chicken meat used as a main protein source in home-made food has also been shown to be an effective and superior remedy for the management of chronic diarrhoea in infants (Godard et al. 1989; Kolacek et al. 1996). BEC has been marketed for an array of chronic diseases (Xu \& Sim, 1997), and the exciting novel findings from the present study, together with those of other investigators, would be a good basis for further research on meat extract and cardiovascular diseases.

\section{References}

Ardaillou R \& Chansel D (1996) Angiotensin IV, a new component of the renin angiotensin system with renal effects. Bulletin de l'Academie Nationale de Medecine (Paris) $\mathbf{1 8 0}$, 475-488.

Corman B, Duriez M, Poitevin P, Heudes D, Bruncval P, Tedgui A \& Levy BI (1998) Aminoguanidine prevents age-related arterial stiffening and cardiac hypertrophy. Proceedings of the National Academy of Sciences USA 93, 1301-1306.

Ferrario CM, Chappell MC, Tallent EA, Brosniham KB \& Diz DI (1997) Counterregulatory actions of angiotensin-(1-7). Hypertension 30, 535-541.

Freeman EJ, Chisolm GM, Ferrario CM \& Tallant EA (1996) Angiotensin-(1-7) inhibits vascular smooth muscle cell growth. Hypertension 28, 104-108.

Geissler C (1988) Effects of chicken essence on metabolic rate and blood restoration. Proceedings of the Nutrition Society 47, $49-53$.

Geissler G, Boroumand-Naini M \& Tomassen C (1989) Large acute thermic response to chicken essence in humans. Nutrition Reports International 39, 547-556.

Godard C, Bustos M, Munoz M \& Nussle D (1989) Value of a chicken-base formula for refeeding of children with protracted diarrhea and malnutrition in a developing country. Journal of Pediatric Gastroenterology and Nutrition 9, 473-480.

Ieki K, Yazaki Y, Yamaoki K, Tsuchimochi H, Yoshizumi M \& Komuro I, et al. (1989) Effect of long-term treatment with betablocker on cardiac hypertrophy in SHR. Journal of Molecular and Cellular Cardiology 21, Suppl. 5, 113-119.

Ishiye M, Umemura K, Uematsu T \& Nakashima M (1995) Effect of losartan, an angiotensin II antagonist, on the development of cardiac hypertrophy due to volume overload. Biological and Pharmaceutical Bulletin 18, 700-704.

Kolacek S, Grguric J, Percl M \& Booth IW (1996) Home-made modular diet versus semi-elemental formula in the treatment of chronic diarrhoea of infancy: a prospective randomised trial. European Journal of Pediatrics 155, 997-1001.

Min L, Sim MK \& Xu XG (2000) Effects of des-aspartateangiotensin II on the angiotensin II-induced incorporation of phenylalanine and thymidine in cultured rat cardiomyocytes and aortic smooth muscle. Regulatory Peptides 95, 93-97.

Miwa M, Shibata K, Nagayama K \& Aikawa K (1997) Nitric oxide formation by macrophages stimulated with water extracts from meat and offals. Bioscience, Biotechnology and Biochemistry 61, 1953-1954.

Mizuno K, Tani M, Hashimoto S, Niimura S, Sanada H, Watanabe H, Ohtsuki M \& Fukuchi S (1992) Effects of losartan, a nonpeptide angiotensin II receptor antagonist on cardiac hypertrophy and tissue angiotensin II content in spontaneously hypertensive rats. Life Sciences 51, 367-374.

National Institutes of Health (1996) Guide for the Case and use of Laboratory Animals. NIH Publication no. 85-23, Bethesda, MD: National Institutes of Health.

Peters KG, Wangler RD, Tomanek RJ \& Marcus M (1984) Effects of long-term cardiac hypertrophy on coronary vasodilator reserve in SHR rats. American Journal of Cardiology 54, 1342-1348.

Ruzicka M, Yuan B \& Leenen FH (1994) Effects of enalapril versus losartan on regression of volume overload-induced cardiac hypertrophy in rats. Circulation 90, 484-491.

Sim MK \& Min L (1998) Effects of des-Asp-angiotensin I on experimentally-induced cardiac hypertrophy in rats. International Journal of Cardiology 63, 223-227.

Sim MK \& Radhakrishnan R (1994a) Novel central action of desAsp-angiotensin I. European Journal of Pharmacology 259, 87-90.

Sim MK \& Radhakrishnan R (1994b) In vivo study of angiotensin tachyphylaxis in freely moving normo- and hypertensive rats. Pharmacology and Toxicology 74, 223-227.

Sperber AD, Galil A, Sarov B, Stahl Z \& Shany S (1996) A combined community strategy to reduce cholesterol and other risk factors. American Journal of Preventive Medicine 12, 123128.

Tinbergen BJ \& Slump P (1976) The detection of chicken meat in meat products by means of the anserine/carnosine ratio. Zeitschrift für Lebensmittel Untersuchung und Forschung 161, 7-11.

Williams AT \& Schey SA (1993) Use of traditional blood remedy. A study on regular donors. International Food Science and Nutrition 44, 17-20.

Xu CL \& Sim MK (1997) Effect of oral feeding of essence of chicken on the level of 5-hydroxyindole acetic acid in the cerebrospinal fluid of the rat. International Journal of Food Sciences and Nutrition 48, 113-117.

Younes A, Boluyt MO, O'Neill L, Meredith AL, Crow MT \& Lakatta EG (1995) Age-associated increase in rat ventricular ANP gene expression correlates with cardiac hypertrophy. American Journal of Physiology 269, H1003-H1008. 